\title{
Characterization of Sarcoptes scabiei cofilin gene and assessment of recombinant cofilin protein as an antigen in indirect- ELISA for diagnosis
}

Yu Zheng ${ }^{1+}$, Ran $\mathrm{He}^{1 \dagger}$, Manli He ${ }^{1}$, Xiaobin Gu${ }^{1}$, Tao Wang ${ }^{1}$, Weimin Lai $^{1}$, Xuerong Peng ${ }^{2}$ and Guangyou Yang ${ }^{1 *}$

\begin{abstract}
Background: Scabies impairs the health of humans and animals and causes heavy economic losses. Traditional diagnostic methods for scabies are inefficient and ineffective, and so far there is no commercial immunodiagnostic or molecular based test for scabies.

Methods: Here, we used recombinant Sarcoptes scabiei cofilin protein as an antigen to establish indirect ELISA. S. scabiei cofilin is highly homologous to Dermatophagoides farinae Der f 31 allergen (90 \% identity). The S. scabiei cofilin gene was cloned and expressed in Escherichia coli to obtain recombinant protein. Western blotting and fluorescence immunohistochemistry were carried out, and we established an indirect ELISA method and detected 33 serum samples from scabies infected rabbits and 30 serum samples from naïve rabbits.

Results: Western blotting demonstrated that $S$. scabiei cofilin possessed good immunogenicity and fluorescence immunohistochemistry showed the S. scabiei cofilin is widespread in the splanchnic area of mites. In ELISA, a cut-off value of 0.188 was determined to judge experimental positive and negative serum values. Specificity and sensitivity of the ELISA were 87.9 and $83.33 \%$, respectively.

Conclusions: Recombinant S. scabiei cofilin showed potential value as a diagnostic antigen. The ELISA method established could be used in clinical diagnosis and provide experimental information in minimal or asymptomatic infection.
\end{abstract}

Keywords: Sarcoptes scabiei, Cofilin, Immunohistochemistry, ELISA

\section{Background}

Sarcoptes scabiei, as an ectoparasite, causes a disease named scabies which spreads worldwide in humans and companion animals, livestock and wildlife, such as dogs, sheep, goats, foxes, raccoons, camels, wombats, etc. Mites burrow into the stratum granulosum of the skin, feeding on epidermal cells and serum [1], and cause an intensely pruritic rash, which is usually more apparent at night [2]. Heavy scabiei named "crusted scabies" may immunocompromise patients, leading to severe damage

\footnotetext{
* Correspondence: guangyou1963@aliyun.com

${ }^{\dagger}$ Equal contributors

'Department of Parasitology, College of Veterinary Medicine, Sichuan

Agricultural University, Wenjiang, China

Full list of author information is available at the end of the article
}

of skin on a large scale or even death [3]. Scabiei can also facilitate secondary infection, resulting in a series of additional and serious complications, such as streptococcal infection, which can finally cause chronic kidney disease $[4,5]$. Scabies impairs the quality of life in humans [6]. In animals, pruritus and hypersensitive dermatitis caused by mites may lead to economic loss because of depression in growth and feed conversion rates. Many countries and international organizations realize the importance of scabies, which is listed among the top 50 most prevalent diseases worldwide [7] and is treated as a "neglected tropical disease" [8].

Recently, an increasing number of S. scabiei antigens have been characterized and explored to reveal their role in mites and in the relationship between mites and hosts 
[9]. It is practical to produce S. scabiei recombinant proteins, which are useful tools to understand the biology of the mite and the immune responses of parasites and hosts. However, no commercial immunodiagnostic or molecular based tests are currently available for scabies.

Traditional diagnostic methods for scabies are normally based on clinical symptoms and on observed scratching of mites from patients and infected animals. Diagnosis depends on experienced physicians and the number of mites on infested hosts. It is hard to distinguish scabies from eczema, hairless tinea, lice and crab lice because of similar symptoms [10, 11]. As seroantibody is generated before the emergence of clinical symptoms, using S.scabiei antigens to detect antibodies in enzyme-linked immunosorbent assay (ELISA) is a promising diagnostic avenue. ELISA could be efficient and effective for the early stage diagnosis of infection and the examination of patients and infested animals [12].

Cofilin, a member of the actin depolymerizing factor (ADF) family, exists in nearly all types of eukaryotic cells and plays important roles [13]. Especially in the modulation of actin dynamics [14] and is involved with various cell activities because of the essential function of actin in many processes such as cell migration, morphogenesis, endocytosis and cytokinesis $[15,16]$. There has been much research on the functions of cofilins in parasites. Tammana et al. [17] deleted the ADF/cofilin gene of Leishmania, which resulted in several aberrations in the process of cell division. Kumar et al. [18] found the overexpression of $\mathrm{ADF} / \mathrm{cofilin}$ protein impaired flagellum assembly and consequently cell motility in Leishmania donovani [17, 18]. Makioka et al. [19] analyzed three ADF/cofilin family proteins of Entamoeba invadens in relation to encystation and excystation. Additionally, experiments on cofilin have been conducted in Trypanosoma brucei, Eimeria tenella, Cryptocaryon irritans, Toxoplasma gondii and Plasmodium falciparum [20-26].

This study reports the cloning, expression and fluorescent immunolocalization of $S$. scabiei cofilin and an assessment of recombinant cofilin protein for diagnosis of scabies by ELISA.

\section{Methods}

\section{Source and sera}

Sarcoptes scabiei maintained on rabbits in Parasite Laboratory of Sichuan Agricultural University were harvested and unfed before handling. Total RNA was extracted from mites using an RNA isolation kit (Waston, Shanghai, China) and transcribed into cDNA using a cDNA synthesis kit (Fermentas); cDNA was stored at $-70{ }^{\circ} \mathrm{C}$ until assay.

Thirty-three blood samples were collected from rabbits infected with S. scabiei and 30 blood samples were collected from naïve rabbits to test cross-reactions, serum samples were also collected from rabbits infected with Psoroptes cuniculi and Cysticercosis pisiformis. All blood samples were stored at $-20^{\circ} \mathrm{C}$.

New Zealand rabbits were used in this study and were handled in strict accordance with the animal protection laws of the People's Republic of China (a draft of an animal protection law in China was released on September 18, 2009). All procedures were carried out in strict accordance with the Guide for the Care and Use of Laboratory Animals by the Animal Ethics Committee of Sichuan Agricultural University (Ya'an, China) (Approval No. 2011-028).

\section{Cloning of cofilin gene and sequence analysis}

The cofilin gene of S. scabiei, identified from NCBI within an expressed sequence tag (EST) (GenBank: BG817660), was amplified with primers which were designed using Primer 5.0 Software (forward primer: 5 -AAATGGCC TCAGGTGTAACT-3 ; reverse primer: 5 -GGTGGGT 2233GAGATAATTTAGTTTC-3 ) (Invitrogen, Beijing, China). The PCR cycling conditions were: $94{ }^{\circ} \mathrm{C}$ for $5 \mathrm{~min}$, 30 cycles of amplification at $94{ }^{\circ} \mathrm{C}$ for $1 \mathrm{~min}, 56{ }^{\circ} \mathrm{C}$ for $1 \mathrm{~min}$, and $72^{\circ} \mathrm{C}$ for $1 \mathrm{~min}$, followed by a final extension step at $72{ }^{\circ} \mathrm{C}$ for $30 \mathrm{~min}$. After extraction and purification using a QIAquick Gel Extraction Kit, PCR products were cloned into vector pMD19-T (TaKaRa Bio Co. Ltd., Dalian, China). Then the plasmid was transformed into Escherichia coli strain DH5a (Fermentas) and sequenced by Invitrogen (Beijing, China). The amplified DNA sequence was analyzed and compared with the EST of $S$. scabiei cofilin using DNAMAN Software and compared against the NCBI database utilizing BLAST (http:// www.ncbi.nlm.nih.gov/).

\section{Expression and purification of recombinant cofilin}

$\mathrm{BamHI}$ and $\mathrm{Xhol}$ restriction enzymes were used to digest S.scabiei cofilin DNA fragments which were amplified by primers with the corresponding restriction sites (forward primer: 5 -CGCGGATCCATGGCCTCAGGTGTAAC T-3 ; reverse primer: 5 -CCGCTCGAGGGTGAGA TAATTTAGTTTC-3 ), using S.scabiei cDNA as template. The digested DNA fragments were then ligated into pET-32a $(+)$ (Novagen, Germany) and transformed into E. coli $\mathrm{DH} 5 \alpha$ cells. After certifying these clones were positive by colony-PCR, recombinant plasmids were extracted and transformed into E. coli BL21 (DE3) (Novagen) for protein expression. Subsequently, bacteria for expression were cultivated overnight in $1 \mathrm{~L} \mathrm{LB}$ medium at $37{ }^{\circ} \mathrm{C}$ and then induced for $4 \mathrm{~h}$ using isopropyl- $\beta$-D-thiogalactopyranoside (IPTG) at a final concentration of $1 \mathrm{mM}$. The expression of recombinant cofilin was confirmed by SDS-PAGE and Ni-IDA Sefinose $^{\text {nat }}$ Resin (Bio-Rad) was used to purify the recombinant 
protein. The concentration of the purified protein was determined by biophotometer (Eppendorf).

\section{Western blotting}

Recombinant cofilin protein was detected by SDS-PAGE and transferred to a nitrocellulose membrane for $1 \mathrm{~h}$ in an electrophoretic transfer cell (Bio-Rad, USA). At room temperature, the membrane was blocked in TBST (40 mM Tris- $\mathrm{HCl}, 0.5 \mathrm{M} \mathrm{NaCl}, 0.1$ Tween 20, pH 7.4) in $5 \%$ skimmed milk for $2 \mathrm{~h}$ and then incubated with rabbit antiserum (diluted 1:200 with $1 \%$ skimmed milkTBST) overnight. Next, the membrane was washed three times using TBST, each for $5 \mathrm{~min}$, before being incubated with horseradish peroxidase (HRP)-conjugated goat anti-rabbit antibody (diluted 1:1000) for $1 \mathrm{~h}$. The membrane was then washed as before, and protein signals were detected using diaminobenzidine (DAB) reagent (Tiangen, China).

\section{Fluorescence immunohistochemistry}

In order to perform immunolocalization studies of Sarcoptes scabiei, antiserum against S. scabiei cofilin was raised in rabbits. Rabbit sera were collected before immunizing to provide reagents for negative controls. For the first immunization, $200 \mu \mathrm{g}$ recombinant S. scabiei cofilin emulsified with equal volumes of Freund's complete adjuvant (Sigma, USA) was injected subcutaneously. The second and third injection for boosting immunization were given mixing $100 \mu \mathrm{g}$ protein with equal volumes of Freund's incomplete adjuvant at a 2week interval. Two weeks after the final injection, rabbit antisera were collected. The antibody titer was determined by ELISA. The immunoglobulin G (IgG) was further isolated from antisera using a Protein G- Sepharose column (Bio-Rad, USA).

Mites were fixed in $1 \%$ molten agarose and set in paraffin wax after solidification of the molten agarose, followed by using a rotary microtome to cut embedded mites into $5 \mu \mathrm{m}$ thick sections. The sections were then rehydrated by immersing the slides successively in xylene twice for $10 \mathrm{~min}$ each, $100 \%$ ethanol twice for $10 \mathrm{~min}$ each, $95 \%$ ethanol for $5 \mathrm{~min}, 70 \%$ ethanol for $5 \mathrm{~min}, 50 \%$ ethanol for $5 \mathrm{~min}$ and lastly rinsing the slides with deionized $\mathrm{H}_{2} \mathrm{O}$. Slides were treated to inactivate endogenous peroxidase by incubating in blocking buffer $\left(3 \% \mathrm{H}_{2} \mathrm{O}_{2}\right.$ in PBS) for $15 \mathrm{~min}$ at $37{ }^{\circ} \mathrm{C}$ and then immersed in $0.01 \mathrm{M}$ sodium citrate buffer solution (pH 6.0) at $95{ }^{\circ} \mathrm{C}$ for $15 \mathrm{~min}$ for heat-induced epitope retrieval. After incubating in blocking buffer $(5 \%$ BSA in PBS) for $1 \mathrm{~h}$ at room temperature, tissue sections were then incubated with specific rabbit anticofilin antibodies (diluted 1:100 in TBS) overnight at $4{ }^{\circ} \mathrm{C}$. After washing three times with TBS, the sections were then incubated with fluorescein isothiocyanate (FITC) goat anti-rabbit IgG $(\mathrm{H}+\mathrm{L})$ (AMRESCO, Texas, USA) (diluted 1:100) in $0.1 \%$ Evans blue, at $37{ }^{\circ} \mathrm{C}$, in the dark, for $1 \mathrm{~h}$. From this step forward, samples were protected from light. Slides were mounted with an anti-fade mounting media and visualized using a fluorescence microscope.

\section{Set-up of indirect ELISA and detecting serum samples}

After optimizing the conditions for ELISA, this procedure was followed: each well of a 96-well plate was coated with $100 \mu \mathrm{L}$ purified recombination cofilin protein overnight at $4{ }^{\circ} \mathrm{C}$. The protein was diluted in PBS-T $\left(16 \mathrm{mM} \mathrm{Na} \mathrm{HPO}_{4}, 5 \mathrm{mM} \mathrm{NaH} \mathrm{PO}_{4}, 120 \mathrm{mM}\right.$ $\mathrm{NaCl}, 0.05 \%$ Tween $20, \mathrm{pH} 7.4$ ) to a concentration of $5 \mu \mathrm{g} / \mathrm{mL}$ in advance. The next day, plates were washed with PBS-T three times, each wash for $5 \mathrm{~min}$, and then incubated with blocking buffer (0.5) dried skimmed milk) at $37{ }^{\circ} \mathrm{C}$ for $2 \mathrm{~h}$. From this step forward, plates were washed with PBS-T between incubations as described above. Serums to be tested in the ELISA were diluted 1:100 in PBS-T and $100 \mu \mathrm{L}$ of the diluted serum solution were added to every well and incubated for $45 \mathrm{~min}$ at $37{ }^{\circ} \mathrm{C}$. Then, the secondary antibody (goat anti-rabbit IgG-horseradish peroxidase (HRP) antibody) diluted 1:3000 in PBS-T was added and incubated for $1 \mathrm{~h}$ at $37{ }^{\circ} \mathrm{C}$. To reveal the reaction, the substrate 3,3,5,5-tetramethylbenzidine (TMB) was added to every well $(100 \mu \mathrm{L})$ and incubated for $15 \mathrm{~min}$. Lastly, the same volume of $1 \mathrm{M}$ $\mathrm{H}_{2} \mathrm{SO}_{4}$ was added to stop the coloration and plates were read in an ELISA-reader at an absorbance of $450 \mathrm{~nm}$ to determine the optical densities (OD).

In total, 33 serum samples from scabies infected rabbits and 30 negative controls from naïve rabbits were tested. Serum samples from rabbits infected with $P$. cuniculi $(n=6)$ or $C$. pisiformis $(n=6)$ were used as controls for the determination of cross-reactivity. Experimental controls including background (all antibodies replaced with PBS-T), omission of antigen, omission of primary antibody and omission of secondary antibody were included.

\section{Statistical analysis}

As a measure of potential diagnostic performance, sensitivity and specificity were calculated: Sensitivity = ELISA positive samples/S. scabiei infected samples $\times 100 \%$; Specificity $=$ ELISA negatives samples $/ S$. scabiei noninfected samples $\times 100 \%[27,28]$. The cut-off value between negative and positive results was calculated as the average measurement of the mange negative animals plus three times the standard deviation [29-31]. The coefficient of variation (CV) and the concordance correlation coefficient $(\mathrm{CCC})$ were calculated by estimating 


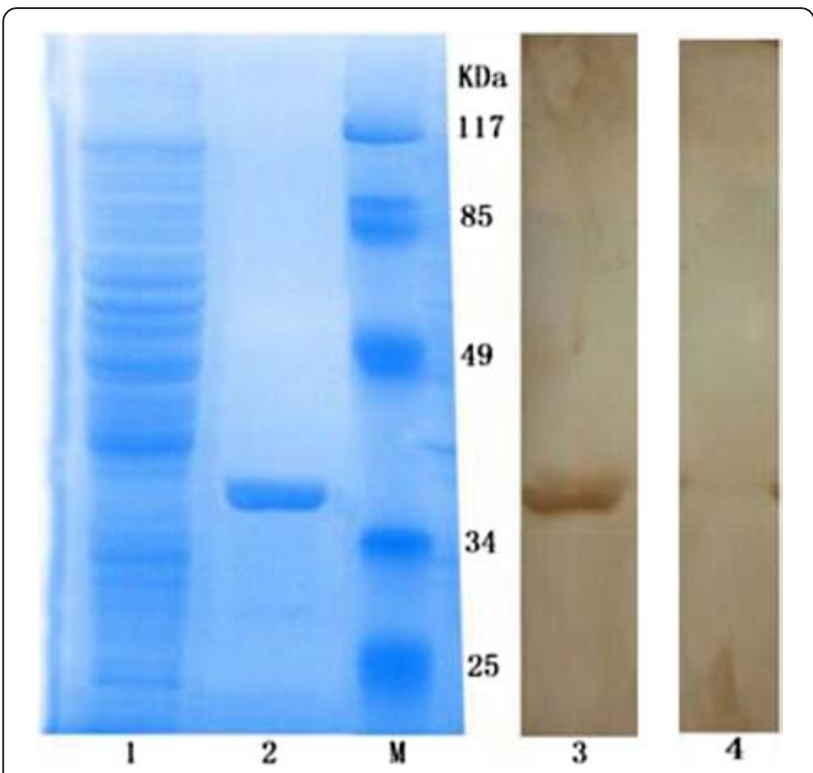

Fig. 1 SDS-PAGE and Western blot of recombinant cofilin. Lanes: $M$ : Protein molecular weight markers; 1 : Whole cell extracts from noninduced cells containing pET32a-cofilin; 2: purified recombinant cofilin; 3: Western blot detection with S. scabiei infected rabbit antisera 4: Western blot detection with naïve serum

the repeatability of the same samples measured within and between plates [32, 33].

\section{Results}

\section{Recombinant cofilin and sequence analysis}

The clone of the S. scabiei cofilin gene was sequenced and compared against the NCBI database utilizing BLAST searching. The S. scabiei cofilin gene, consisting of 447 nucleotides, encoded 148 amino acids and was predicted to translate to a $16.8 \mathrm{kDa}$ outer membrane protein. After optimizing the expression conditions, recombinant S. scabiei cofilin protein was produced by $E$. coli BL21 (DE3). Then a Ni-chelating column was used to purify the recombinant protein, which was examined by SDS-PAGE (Fig. 1).
Western blotting and fluorescence immunohistochemistry The recombinant protein reacted with sera from scabiei infested rabbits and there was no reaction between recombinant protein and negative sera (Fig. 1). Fluorescence immunohistochemistry showed S. scabiei cofilin is widespread in the splanchnic area of mites but not in the epidermal integument (Fig. 2).

\section{Indirect ELISA}

The optimal coating concentration of antigen was $5 \mu \mathrm{g} /$ $\mathrm{mL}$, and the optimal working dilution of serum and secondary antibody was $1: 100$ and $1: 3000$, respectively. The cut-off value was 0.188 ; if $\mathrm{OD}_{450} \geq 0.188$, the serum was determined as positive, if $\mathrm{OD}_{450}<0.188$, the serum was classed as negative. There was no significant crossreactivity between the cofilin recombinant antigen and serum from rabbits infected with $P$. cuniculi or $C$. pisiformis (Fig. 3). The CV was 1.28-4.08 \% and the CCC was $1.81-5.30 \%$. The sensitivity and specificity of the assay were calculated as 83.33 and $87.9 \%$, respectively (Fig. 4). Thus, recombinant S. scabiei cofilin protein has value as an antigen to be used in indirect ELISA for the diagnosis of scabiei.

\section{Discussion}

This study characterized the S. scabiei cofilin gene and used its recombinant protein as an antigen in indirect ELISA for detecting the antibody in rabbit serum.

Western blotting showed the good immunogenicity of the S. scabiei cofilin protein and there was no band in negative controls. In fluorescence immunohistochemistry assay, S. scabiei cofilin located widely in the mites, which could be explained by the relationship between cofilin and actin.

Methods using recombinant allergens to diagnose parasite diseases such as infection with nematodes, cestodes, protozoa, hydatids and acaria are becoming prevalent [34-36]. Among these studies, recombinant antigens from mites such as thioredoxin peroxidase, Sar s 14.3, Pso o 2, Ss $\lambda 20 \Delta 3$ showed potential value for diagnosis. Sar s 14.3
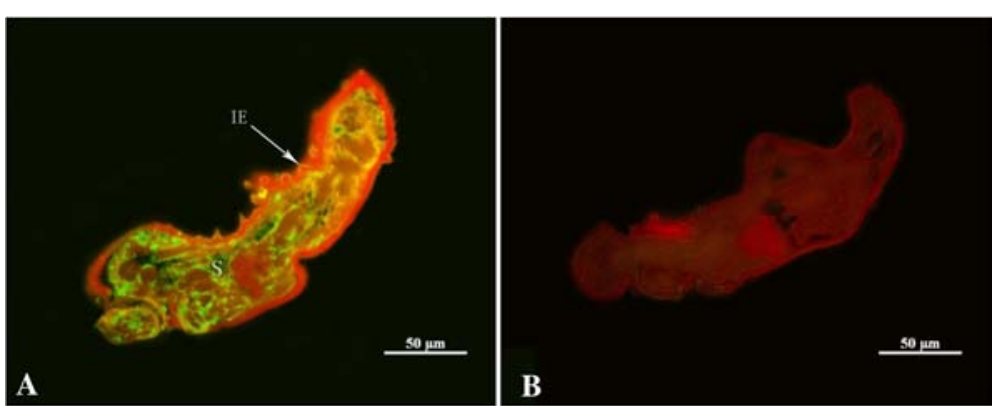

Fig. 2 Immunolocalization of cofilin in sections of Sarcoptes scabiei. Panel a: staining with anti-cofilin as primary antibody; Panel b: control (no primary antibody). Annotation: S, splanchnic area; IE, epidermal integument 


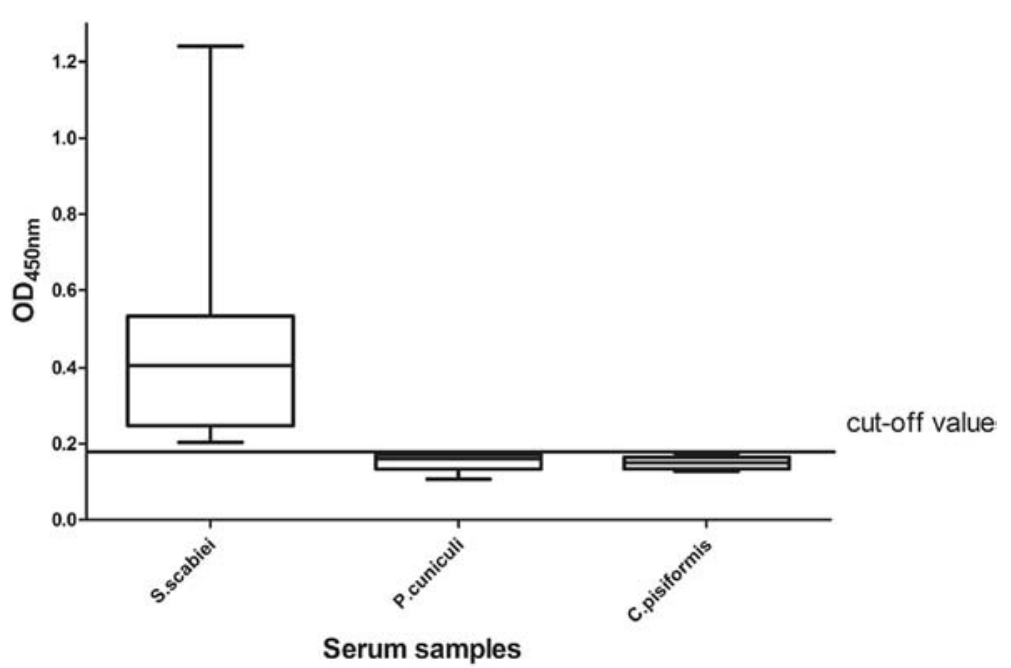

Fig. 3 Cross-reactivity in ELISA between S. scabiei, P. cuniculi and C. pisiformis. S.scabie: $\mathrm{OD}_{450} \mathrm{~nm}$ results of serums from S.scabie infected rabbits; P. cuniculi: $\mathrm{OD}_{450} \mathrm{~nm}$ results of serums from P. cuniculi infected rabbits; C. pisiformis: $\mathrm{OD}_{450} \mathrm{~nm}$ results of serums from C. pisiformis infected rabbits

and Pso o 2 are homologous with the allergens Der $\mathrm{p} 14$ and Der f 2 of house dust mite, respectively [37-39]. Many allergens of house dust mite have been explored for diagnosis, of which Der $\mathrm{p} 1$ is used for a reliable ELISA kit [40]. In our study, S. scabiei cofilin showed highly homology (90 \% identity) with Der f 31, so it can be deduced that S. scabiei cofilin has potential value in exploring a standard procedure to diagnose scabies.

Although we observed no cross-reactivity between the recombinant cofilin antigen and the serum from rabbits infested with P. cuniculi or C. pisiformis, the $\mathrm{OD}_{450 \mathrm{~nm}}$ of these samples were all close to the cut-off value. This phenomenon might result in error judgment for those data close to threshold, and illustrate cross-reactivity that cannot be clearly determined might exist; further study is need to solve this problem. CV (1.28-4.08\%) and CCC (1.81-5.30\%) values demonstrated that the operation of the ELISA was reliable.

We determined a cut-off value of 0.188 and calculated specificity of $87.9 \%$ and sensitivity of $83.33 \%$. In recent research on diagnosis of $S$. scabiei, a study using recombinant Sar s 14.3 protein as antigen in dissociationenhanced lanthanide fluorescent immunoassays (DELFIA) achieved $100 \%$ sensitivity and $93.75 \%$ specificity [37]. Kuhn immunoscreened six clones of sarcoptic mites to evaluate those expressed recombinant proteins as

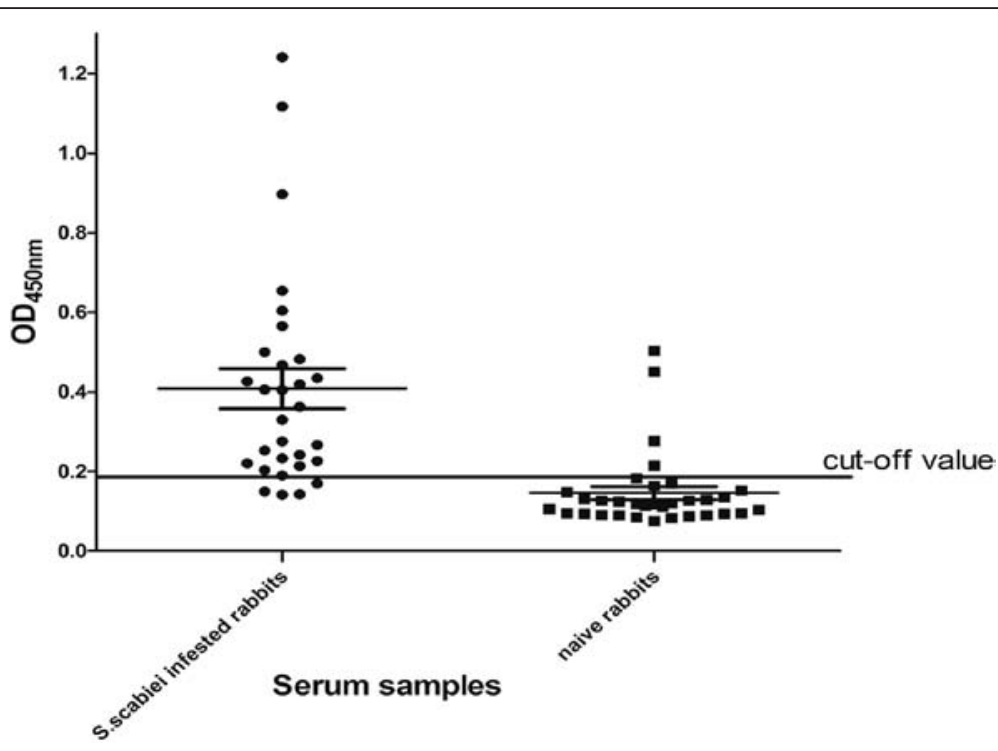

Fig. 4 ELISA of serum samples from S. scabiei infected rabbits and naïve rabbits 
diagnostic antigens, in which the sensitivity ranged from 0 to $61.9 \%$ [41]. The results of similar diagnostic research using recombinant proteins vary, probably because of the difference in the diagnostic assay applied in each study and/or the diversity in intrinsic characteristics of each antigen. According to Moendeg, cocktail-ELISA, mixing several good diagnostic antigens, might improve diagnostic potential and produce a method for multi-host species detection [42]. For scabies, further research is essential to establish a unified diagnostic method. Cofilin could be a potential diagnostic antigen for future diagnostic studies of scabies.

\section{Conclusions}

In general, S.scabiei cofilin is widespread in the splanchnic area of S. scabiei. Recombinant S. scabiei cofilin showed potential value as a diagnostic antigen. S.scabiei cofilin based indirect ELISA for detection of scabies in animals is sensitive and specific, which means the S.scabiei cofilin could be used to develop an ELISA-based serological test for the diagnosis of scabies in animals.

\section{Abbreviations}

ADF: actin depolymerizing factor; Der f: dermatophagoides farina; Der p: dermatophagoides pteronyssinus; P. cuniculi: psoroptes cuniculi; Pso o: psoroptes ovis; S.scabiei, Sar s, Ss: sarcoptes scabiei.

\section{Competing interests}

The authors have declared that no competing interests exist.

\section{Authors' contributions}

YZ participated in the design of the study, manuscript writing and performed the statistical analysis; $\mathrm{RH}$ participated in the write of the manuscript, $\mathrm{RH}$ and $\mathrm{MH}$ participated in the collection of mites samples; $\mathrm{RH}$ and $\mathrm{YZ}$ participated in experiment and discussion; $\mathrm{YZ}$ participated in sequence alignment, $X G$ and TW helped to draft the manuscript; $W L$ and XP provided the support of experiment animals and serum samples; GY participated in the design of study and have given final approval of the version; All authors read and approved the final manuscript.

\section{Acknowledgments}

This study was supported by a grant from the Research Fund (Project No. CPF2014-17) for the Chengdu Research of Giant Panda Breeding.

\section{Author details}

${ }^{1}$ Department of Parasitology, College of Veterinary Medicine, Sichuan Agricultural University, Wenjiang, China. ${ }^{2}$ Department of Chemistry, College of Life and Basic Science, Sichuan Agricultural University, Wenjiang, China.

\section{Received: 21 July 2015 Accepted: 18 January 2016} hult?

\section{References}

1. Holt DC, Burgess STG. Intestinal proteases of free-living and parasitic astigmatid mites. Cell Tissue Res. 2013;351:339-52.

2. Currier RW, Walton SF, Currie BJ. Scabies in animals and humans: history, evolutionary perspectives, and modern clinical management. Ann N Y Acad Sci. 2012;12301:E50-60

3. Karthikeyan K. Crusted scabies. Indian J Dermatol Ve. 2009;75:340-47.

4. Chung SD, Wang KH, Huang CC, Lin HC. Scabies increased the risk of chronic kidney disease: a 5-year follow-up study. J Euracad Dermatol. 2014; 28:286-92.

5. Berríos X, Lagomarsino E, Solar E, Sandoval G, Guzmán B, Riedel I. Poststreptococcal acute glomerulonephritis in Chile-20 years of experience. Pediatr Nephro. 2004;19:306-12.
6. Worth C, Heukelbach J, Fengler G, Walter B, Liesenfeld O, Feldmeier H. Impaired quality of life in adults and children with scabies from an impoverished community in Brazil. Int J Dermatol. 2012;51:275-82.

7. Hay RJ, Johns NE, Williams HC, Bolliger IW, Dellavalle RP, Margolis DJ, et al. The Global burden of skin disease in 2010: an analysis of the prevalence and impact of skin conditions. J Invest Dermatol. 2014;134: 1527-34.

8. Engelman D, Kiang K, Chosidow O, McCarthy J, Fuller C, Lammie P, et al. Toward the global control of human scabies: introducing the international alliance for the control of scabies. Plos Negl Trop Dis. 2013;7:E2167.

9. Fischer K, Walton S. Parasitic mites of medical and veterinary importance-is there a common research agenda? Int J Parasitol. 2014;44:955-67.

10. Walton SF, Currie BJ. Problems in diagnosing scabies, a global disease in human and animal populations. Clin Microbiol Rev. 2007;20:268-79.

11. Walton SF, Holt DC, Currie BJ, Kemp DJ. Scabies: new future for a neglected disease. Adv Parasitol. 2004;57:309-76.

12. Bornstein S, Zakrisson G, Thebo P. Clinical picture and antibody response to experimental Sarcoptes scabiei var. vulpes infection in red foxes (Vulpes vulpes). Acta Vet Scand. 1995;36:509-19.

13. Maciver SK, Hussey PJ. The ADF/cofilin family: actin-remodeling proteins. Genome Biol. 2002;3:3007.

14. Bernstein BW, Bamburg JR. ADF/cofilin: a functional node in cell biology. Trends Cell Biol. 2010;20:187-95.

15. Poukkula M, Kremneva E, Serlachius M, Lappalainen P. Actin-depolymerizing factor homology domain: a conserved fold performing diverse roles in cytoskeletal dynamics. Cytoskeleton (Hoboken). 2011;68:471-90.

16. Bravo-Cordero JJ, Magalhaes MA, Eddy RJ, Hodgson L, Condeelis J. Functions of cofilin in cell locomotion and invasion. Nat Rev Mol Cell Biol. 2013;14:405-15.

17. Tammana TV, Sahasrabuddhe AA, Bajpai VK, Gupta CM. ADF/cofilin-driven actin dynamics in early events of leishmania cell division. J Cell Sci. 2010; 123:1894-901.

18. Kumar G, Srivastava R, Mitra K, Sahasrabuddhe AA, Gupta CM. Overexpression of S4D mutant of leishmania donovani ADF/cofilin impairs flagellum assembly by affecting actin dynamics. Eukaryot Cell. 2012;11:752-60

19. Makioka A, Kumagai M, Hiranuka K, Kobayashi S, Takeuchi T. Entamoeba invadens: identification of ADF/cofilin and their expression analysis in relation to encystation and excystation. Exp Parasitol. 2011;127:195-201.

20. Dai K, Liao S, Zhang J, Zhang X, Tu X. Structural and functional insight into ADF/cofilin from Trypanosoma brucei. PLoS One. 2013;8:E53639.

21. Zhou BH, Wang HW, Xue FQ, Wang XY, Yang FK, Ban MM, et al. Actindepolymerising factor of second-generation merozoite in Eimeria tenella: clone, prokaryotic expression and diclazuril-induced mRNA expression. Parasitol Res. 2010;106:571-76.

22. Huang X, Xu Y, Guo G, Lin Q, Ye Z, Yuan L, et al. Molecular characterization of an actin depolymerizing factor from Cryptocaryon irritans. Parasitology. 2013;140:561-68.

23. Allen ML, Dobrowolski JM, Muller H, Sibley LD, Mansour TE. Cloning and characterization of actin depolymerizing factor from Toxoplasma gondii. Mol Biochem Parasitol. 1997;88:43-52.

24. Ueno A, Dautu G, Saiki E, Haga K, Igarashi M. Toxoplasma gondii deoxyribose phosphate aldolase-like protein (TgDPA) interacts with actin depolymerizing factor (TgADF) to enhance the actin filament dynamics in the bradyzoite stage. Mol Biochem Parasitol. 2010;173:39-42.

25. Yadav R, Pathak PP, Shukla VK, Jain A, Srivastava S, Tripathi S, et al. Solution structure and dynamics of ADF from Toxoplasma gondii. J Struct Biol. 2011; 176:97-111.

26. Doi Y, Shinzawa N, Fukumoto S, Okano H, Kanuka H. ADF2 is required for transformation of the ookinete and sporozoite in malaria parasite development. Biochem Biophys Res Commun. 2010;397:668-72.

27. Rampton M, Walton SF, Holt DC, Pasay C, Kelly A, Currie BJ, et al. Antibody responses to Sarcoptes scabiei apolipoprotein in a porcine model: relevance to immunodiagnosis of recent infection. PLoS One. 2013;8:E65334.

28. Yang D, Chen L, Wu X, Zhou X, Li M, Chen Z, et al. Expression of the Tpanxb1 gene from Cysticercosis pisiformis and its potential diagnostic value by dot-ELISA. J Parasitol. 2014;100:246-50.

29. Sarkari B, Ashrafmansouri M, Hatam G, Habibi P, Abdolahi KS. Performance of an ELISA and indirect immunofluorescence assay in serological diagnosis of zoonotic cutaneous leishmaniasis in iran. Interdiscip Perspect Infect Dis. 2014;2014:505134. 
30. Bornstein S, Wallgren P. Serodiagnosis of sarcoptic mange in pigs. Vet Rec 1997;141:8-12

31. Riyong D, Waikagul J, Panasoponkul C, Choochote W, Ito A, Dekumyoy P. Size and charge antigens of Dirofilaria immitis adult worm for lgG-ELISA diagnosis of bancroftian filariasis. Southeast Asian Trop Med Public Health. 2010:41:285-97.

32. Casais R, Goyena E, Martínez-Carrasco C, Ruiz de Ybáñez R, Alonso de Vega $F$, Ramis $G$, et al. Variable performance of a human derived Sarcoptes scabiei recombinant antigen ELISA in swine mange diagnosis. Vet Parasitol. 2013;197:397-403.

33. Grabias B, Zheng H2, Mlambo G3, Tripathi AK4, Kumar S. A sensitive enhanced chemiluminescent-ELISA for the detection of Plasmodium falciparum circumsporozoite antigen in midguts of Anopheles stephensi mosquitoes. J Microbiol Methods. 2015;108:19-24.

34. Vlaminck J. Evaluation of Ascaris suum haemoglobin as a vaccine and diagnostic antigen. http://hdl.handle.net/1854/LU-3116855 (2013). Accessed 31 Jan 2013.

35. Döşkaya M, Caner A, Can H, Gülçe Iz S3, Gedik Y4, Döşkaya AD, et al. Diagnostic value of a rec-ELISA using Toxoplasma gondii recombinant SporoSAG, BAG1, and GRA1 proteins in murine models infected orally with tissue cysts and oocysts. PLoS One. 2014;9:E108329.

36. Zheng $W$, Zhang $R$, Wu X, Ren $Y$, Nong $X$, Gu X, et al. Evaluating troponin $C$ from Psoroptes cuniculi as a diagnostic antigen for a dot-ELISA assay to diagnose mite infestations in rabbits. Parasite Immunol. 2014;36:53-9.

37. Jayaraj R, Hales B, Viberg L, Pizzuto S, Holt D, Rolland JM, et al. A diagnostic test for scabies: IgE specificity for a recombinant allergen of Sarcoptes scabiei. Eiagn Microbiol Infect Dis. 2011;71:403-7.

38. Nunn FG, Burgess ST, Innocent G, Nisbet AJ, Bates P, Huntley JF. Development of a serodiagnostic test for sheep scab using recombinant protein Pso o 2. Mol Cell Probes. 2011;25:212-18.

39. Zhang $R$, Zheng W, Wu X, Jise $Q$, Ren $Y$, Nong $X$, et al. Characterisation and analysis of thioredoxin peroxidase as a potential antigen for the serodiagnosis of sarcoptic mange in rabbits by dot-ELISA. BMC Infect Dis. 2013;13:336.

40. van Oeveren W, ten Brinke O, van der Graaf K. Development of a enzymelinked immunosorbent assay kit for determination of the major allergen from dermatophagoides pteronyssinus, Der p1, house dust mite. ALLERGY. NJ: Wiley-blackwell; 2011. p. 529.

41. Kuhn C, Lucius R, Matthes HF, Meusel G, Reich B, Kalinna BH. Characterisation of recombinant immunoreactive antigens of the scab mite Sarcoptes scabiei. Vet Parasitol. 2008;153:329-37.

42. Moendeg KJ, Angeles JM, Goto Y, Leonardo LR, Kirinoki M, Villacorte EA, et al. Development and optimization of cocktail-ELISA for a unified surveillance of zoonotic schistosomiasis in multiple host species. Parasitol Res. 2015;114:1225-8.

\section{Submit your next manuscript to BioMed Central and we will help you at every step:}

- We accept pre-submission inquiries

- Our selector tool helps you to find the most relevant journal

- We provide round the clock customer support

- Convenient online submission

- Thorough peer review

- Inclusion in PubMed and all major indexing services

- Maximum visibility for your research

Submit your manuscript at www.biomedcentral.com/submit
Biomed Central 